\title{
PENGETAHUAN DAN SIKAP PERAWAT TERHADAP PENANGANAN MASALAH PSIKOLOGIS DAN SPIRITUAL PADA PASIEN PASCA BENCANA: A COMPARATIVE STUDY
}

\author{
Cut Husna ${ }^{1}$, Jeni Elvania ${ }^{2}$ \\ ${ }^{1}$ Departemen Keperawatan Medikal Bedah, Fakultas Keperawatan \\ Universitas Syiah Kuala, Darussalam-Banda Aceh \\ ${ }^{3}$ Mahasiswa Keperawatan Fakultas Keperawatan \\ Universitas Syiah Kuala, Darussalam-Banda Aceh \\ *cuthusna@unsyiah.ac.id
}

\begin{abstract}
Abstrak
Bencana dapat berdampak pada masalah fisik, psikologis, psikososial dan spiritual. Dampak psikologis dapat berupa depresi, marah, putus asa, bunuh diri dan post trauma stress disorder (PTSD). Gangguan spiritual dapat berupa menyalahkan Tuhan, menghindari interaksi dengan orang lain dan merasa bersalah. Hal ini membutuhkan pengetahuan dan sikap perawat dalam penanganan masalah psikologis dan spiritual tersebut. Jenis penelitian adalah comparative study dengan desain cross sectional study. Populasi dalam penelitian ini terdiri dari 124 perawat di Ruang Penyakit Dalam ( $n=92)$ dan Ruang Rawat Bedah $(n=32)$. Alat pengumpulan data berupa kuesioner yang dikembangkan oleh peneliti dalam bentuk skala Dichotomous terdiri dalam 22 pernyataan dan Likert scale terdiri dari 24 pernyataan. Teknik pengumpulan data berupa kuesioner. Data penelitian dianalisis menggunakan analisa bivariat dengan uji independent sample t-test. Hasil penelitian tidak ada perbedaan pengetahuan perawat dalam penanganan masalah psikologis ( $\mathrm{p}$-value $0,106 \mathrm{\alpha}=0,05)$ dan spiritual ( $\mathrm{p}$-value $0,059 \alpha=0,05)$. Ada perbedaan sikap perawat dalam penanganan masalah psikologis ( $\mathrm{p}-$ value $0,001 \alpha=0,05$ ) dan spiritual ( $\mathrm{p}$-value $0,008 \alpha=0,05$ ). Hasil penelitian dapat direkomendasikan kepada pembuat kebijakan untuk meningkatkan program pendidikan dan pelatihan terkait masalah psikologis dan spiritual untuk meningkatkan kompetensi dan sikap profesional perawat dalam memberikan asuhan keperawatan untuk respons bencana.
\end{abstract}

Kata kunci: Pengetahuan, sikap, psikologis, spiritual, perawat, rumah sakit

\begin{abstract}
Disasters may impact on physical, psychological, psychosocial and spiritual problems. The impacts of psychological problems are depression, anger, despair, suicide and post trauma stress disorder (PTSD). Spiritual problems consist of blaming God, avoiding interactions with others and feeling guilty. This requires knowledge and attitudes of nurses in managing psychological and spiritual problems. This research is a comparative study with a cross sectional study design. The population consisted of 124 nurses in the medical ward $(n=92)$ and surgical ward $(n=32)$. Data collection tool is a questionnaire developed by researchers in dichotomous scale consists of 22 items and Likert scale in 24 statements. The research data were analyzed using bivariate with independent sample t-test. The results of the study showed no differences in nurses' knowledge in managing psychological problems (p-value $0.106 \alpha=0.05$ ) and spiritual (p-value $0.059 \alpha=0.05$ ).
\end{abstract}


There are differences in nurses' attitudes in managing psychological problems ( $\mathrm{p}$-value $0.001 \alpha=0.05$ ) and spiritual (p-value $0.008 \alpha=0.05$ ). The results of the study may recommend to policy maker to improve educational and training program related to psychological and spiritual problems to enhance the competency and professional attitude of nurses in providing nursing care for disaster response.

Keywords: Knowledge, attitude, psychological, spiritual, nurse, hospital

\section{Pendahuluan}

Undang-Undang Nomor 24 Tahun 2007 mendefinisikan bencana sebagai peristiwa yang mengancam kehidupan masyarakat, disebabkan oleh faktor alam atau nonalam (faktor manusia) yang mengakibatkan timbulnya korban jiwa, kerusakan lingkungan, kerugian harta benda dan dampak psikologis. Bencana juga diartikan sebagai gangguan serius pada komunitas atau masyarakat luas yang menyebabkan kerusakan materi, ekonomi, lingkungan dan tidak dapat dicegah oleh masyarakat (National Disaster Management Plan, 2016; UU No 24, 2007). Bencana memberikan efek yang buruk bagi korban seperti kehilangan harta benda, tempat tinggal dan kematian anggota keluarga (Priester, 2016).

Badan Nasional

Penanggulangan Bencana (BNPB) mencatat di Indoensia sejak 2018 telah terjadi bencana sebanyak 1.999 kejadian. Data historis bencana menunjukkan bahwa Indonesia mengalami bencana alam dengan jumlah korban jiwa yang besar. Korban bencana meninggal dunia dan hilang sebanyak 3.548 dan sebanyak 3,06 juta orang mengungsi dan terdampak bencana (BNPB, 2018).

Bencana yang terjadi berdampak langsung kepada komunitas dan lingkungan yang dapat mengakibatkan kematian, luka-luka dan korban selamat dari bencana mengalami gangguan emosional dan psikologis (Kalanlar, 2018). Survei Mental
Health and Substance Use Unit Department of Emergency Preparedness and Disaster Relief (2016) menunjukkan bahwa sebesar 3$4 \%$ korban bencana mengalami gangguan psikologis berat dan sebesar $15-20 \%$ mengalami gangguan psikologis ringan. Gempa bumi di Lombok dan Sumbawa, Indonesia pada 2018, menyebabkan 564 orang meninggal dunia dan 445.343 orang mengungsi. Hasil penelitian risiko gangguan jiwa korban bencana alam gempa bumi di Lombok didapatkan sebesar $85,2 \%$ mengalami gangguan neurosis, sebesar $29,5 \%$ mengalami gejala psikotik dan sebesar $64,7 \%$ mengalami gejala post traumatic stress disorder (PTSD) (BNPB, 2018). Korban bencana yang mengalami masalah psikologis menunjukkan gejala seperti cemas, marah, depresi, kesedihan, ketidakberdayaan dan keputusasaan. Apabila masalah psikologis tidak teratasi maka menyebabkan dampak lanjut yaitu post traumatic stress disorder (PTSD) dimana prevalensi PTSD pada korban bencana berkisar antara 4-60\% (Thordardottir, Gudmundsdottir, Petursdottir, Valdimarsdottir, \& Hauksdottir, 2018).

Bencana yang terjadi juga mempengaruhi kondisi spiritual korban bencana. Hal ini disebabkan oleh kejadian bencana yang terjadi secara tiba-tiba dan mengakibatkan kerugian yang besar bagi korban (Priester, 2016). Banyak individu yang 
sangat bergantung pada keyakinan dan praktik keagamaan untuk menghilangkan stres ketika sakit atau terjadi bencana agar dapat mempertahankan harapan, makna dan tujuan hidup. Keterlibatan agama dapat membantu pertumbuhan psikologis yang lebih baik (Koenig, Larson, \& Larson, 2001). Hasil penelitian menunjukkan bawah praktik spiritual berperan penting dalam pemulihan korban bencana. Apabila perawatan psikologis dan spiritual terintegrasi maka akan mendapatkan hasil lebih baik dan holistik sehingga korban bencana lebih adaptif dalam menghadapi bencana (Aten, Grady, Milstein, Boan, \& Schruba, 2014).

Rumah sakit merupakan sentral terdepan penanggulangan korban bencana (Liu, Fowler, Roberts, \& Herovic, 2018). Perawat adalah tim penyedia pelayanan kesehatan terbesar yang berperan penting dalam menanggapi bencana. Sehingga perawat berpengaruh pada respon bencana dan pemulihan korban setelah bencana ( $\mathrm{Li}, \mathrm{Li}$, Yang, \& Xu, 2016). Mengingat dampak psikologis korban bencana yang sangat besar maka diperlukan pengetahuan dan sikap perawat dalam menangani masalah psikologis dan spiritual khususnya. Hasil studi Kiran dan Dewi (2017), melaporkan bahwa pengetahuan perawat dalam pemenuhan kebutuhan psikologis dan spiritual sebesar $(42,9 \%)$ atau baik, sebesar $(41,40 \%)$ berpengetahuan cukup dan sebesar $(15,7 \%)$ berpengetahuan kurang. Sedangkan sikap perawat dalam pemenuhan kebutuhan psikologis dan spiritual, sebesar $61,4 \%$ memiliki sikap yang mendukung dan sebesar $38,6 \%$ memiliki sikap tidak mendukung dalam pemenuhan kebutuhan psikologis dan spiritual pasien. Data ini menunjukkan adanya variasi pengetahuan dan sikap perawat dalam meengatasi masalah gangguan psikologis dan spiritual sebagai dampak dari bencana.

\section{Metode penelitian}

Jenis penelitian adalah descriptive comparative. Teknik pengumpulan data menggunakan kuesioner dalam bentuk skala dichotomous dan Likert scale. Penelitian ini dilakukan di Rumah Sakit Umum Daerah Meuraxa Kota Banda Aceh. Metode pengambilan sampel adalah total sampling. Populasi dalam penelitian ini adalah seluruh perawat pada Ruang Penyakit Dalam (92 orang) dan perawat pada Ruang Rawat Bedah (32 orang) yang total keseluruhan 124 orang. Analisis data menggunakan analisa univariat dan bivariat.

\section{Hasil}

Karaktersitik responden dalam penelitian ini terdiri dari usia, jenis kelamin, agama, pendidikan terakhir, lama kerja dan pelatihan kebencanaan. Untuk penjelasannya dapat dilihat pada tabel berikut:

Tabel 1. Distribusi Karakterstik Responden ( $\mathrm{n}=124)$

\begin{tabular}{ccccc}
\hline \multirow{2}{*}{ Data Demografi } & \multicolumn{2}{c}{ Ruang Penyakit } & \multicolumn{2}{c}{ Ruang Rawat Bedah } \\
\cline { 2 - 5 } & Dalam & $(\%)$ & $(\mathrm{f})$ & $(\%)$ \\
\hline
\end{tabular}




\begin{tabular}{|c|c|c|c|c|}
\hline \multirow[t]{2}{*}{ Data Demografi } & \multicolumn{2}{|c|}{$\begin{array}{l}\text { Ruang Penyakit } \\
\text { Dalam }\end{array}$} & \multicolumn{2}{|c|}{ Ruang Rawat Bedah } \\
\hline & (f) & $(\%)$ & (f) & $(\%)$ \\
\hline \multicolumn{5}{|l|}{ 1. Usia (Tahun) } \\
\hline $17-25$ & 9 & 9,8 & 9 & 28,1 \\
\hline $26-35$ & 67 & 72,8 & 23 & 71,9 \\
\hline $36-45$ & 16 & 17,4 & - & - \\
\hline \multicolumn{5}{|l|}{ 2. Jenis Kelamin } \\
\hline Laki-laki & 15 & 16,3 & 6 & 18,8 \\
\hline Perempuan & 77 & 83,7 & 26 & 81,3 \\
\hline \multicolumn{5}{|l|}{ 3. Agama } \\
\hline Islam & 92 & 100 & 32 & 100 \\
\hline \multicolumn{5}{|l|}{ 4. Pendidikan Terakhir } \\
\hline Diploma III & 62 & 67,4 & 20 & 62,5 \\
\hline Ners & 30 & 32,6 & 12 & 37,5 \\
\hline \multicolumn{5}{|l|}{ 5. Lama Kerja } \\
\hline$<2$ Tahun & 14 & 15,2 & 5 & 15,6 \\
\hline$\geq 2$ Tahun & 78 & 84,8 & 27 & 84,4 \\
\hline \multicolumn{5}{|l|}{ 6.Pelatihan kebencanaan } \\
\hline Tidak ada & 71 & 77,2 & 28 & 87,5 \\
\hline Simulasi keadaan darurat & 14 & 15,2 & 4 & 12,5 \\
\hline $\begin{array}{l}\text { Pelatihan gawat darurat dan } \\
\text { kebencanaan }\end{array}$ & 7 & 7,6 & - & - \\
\hline
\end{tabular}

Tabel 2. Persepsi Perawat Terhadap Masalah Psikologis dan Spiritual Pasca Bencana

\begin{tabular}{|c|c|c|c|c|}
\hline \multirow[t]{2}{*}{ Data } & \multicolumn{2}{|c|}{$\begin{array}{c}\text { Ruang Penyakit } \\
\text { Dalam }\end{array}$} & \multicolumn{2}{|c|}{ Ruang Rawat Bedah } \\
\hline & (f) & $(\%)$ & (f) & $(\%)$ \\
\hline \multicolumn{5}{|l|}{ Masalah psikologis: } \\
\hline Depresi & 24 & 26.1 & 9 & 28.1 \\
\hline Marah & 17 & 18.5 & 10 & 31.1 \\
\hline Kecewa & 10 & 10.9 & 2 & 6.3 \\
\hline Menarik diri & 1 & 1,1 & 2 & 6,3 \\
\hline Menangis & 23 & 25,0 & 6 & 18,8 \\
\hline Apatis & 2 & 2,2 & - & - \\
\hline Merasa bersalah & 1 & 1,1 & - & - \\
\hline Kecemasan & 11 & 12,0 & 3 & 9,4 \\
\hline $\begin{array}{l}\text { Post trauma stress } \\
\text { disorder }\end{array}$ & 2 & 2,2 & - & - \\
\hline Acute stress disorder & 1 & 1,1 & - & - \\
\hline \multicolumn{5}{|l|}{ Masalah spiritual } \\
\hline Putus asa & 47 & 51,1 & 18 & 56,3 \\
\hline Merasa bersalah & 24 & 26,1 & 8 & 25,0 \\
\hline Merasa malu & 7 & 7,6 & - & - \\
\hline Menutup diri & 11 & 12,0 & - & - \\
\hline Menyalahkan tuhan & 3 & 3,3 & 6 & 18,8 \\
\hline
\end{tabular}


Berdasarkan data diatas, menunjukkan bahwa sebagian besar masalah psikologis pada pasien pasca bencana adalah depresi, menangis, marah dan kecemasan. Masalah spiritual yang muncul pada pasien pasca bencana adalah putus asa, merasa bersalah, dan menutup diri.
Hasil pengumpulan data untuk variabel tingkat pengetahuan dan sikap perawat untuk penanganan masalah psikologis dan spiritual yang dilakukan pada 92 perawat di Ruang Penyakit Dalam dan 32 perawat di Ruang Rawat Bedah. Hasil pengkategorian tersebut dapat dilihat pada tabel 3.

Tabel 3. Pengetahuan dan sikap perawat dalam penanganan masalah psikologis dan spiritual

\begin{tabular}{lcccc}
\hline \multirow{2}{*}{ Variabel } & \multicolumn{2}{c}{ Ruang Penyakit Dalam } & \multicolumn{2}{c}{ Ruang Rawat Bedah } \\
\cline { 2 - 5 } & Frekuensi & Persentase & Frekuensi & Persentase \\
\hline Pengetahuan penanganan & & & & \\
masalah psikologis: & 78 & 84,8 & 27 & 84,4 \\
Baik & 14 & 15,2 & 5 & 15,6 \\
Kurang & & & & \\
\hline Pengetahuan penanganan & & & 29 & 90,6 \\
masalah spiritual: & 65 & 70,7 & 3 & 9,4 \\
Baik & 27 & 29,3 & & \\
Kurang & & & & \\
Sikap penanganan masalah & 50 & 54,3 & 18 & 56,3 \\
psikologis: & 42 & 45,7 & & 43,8 \\
Baik & & & & \\
Kurang & & 43,5 & 20 & 62,5 \\
\hline Sikap penanganan masalah & 40 & 56,5 & 12 & 37,5 \\
spiritual: & 52 & &
\end{tabular}

Tabel 4. Distribusi Pengetahuan dan Sikap Perawat dalam Penanganan Masalah Psikologis dan Spiritual Pada Pasien Pasca Bencana

\begin{tabular}{lccccccccc}
\hline & \multicolumn{7}{c}{ Ruang Penyakit Dalam } & \multicolumn{7}{c}{ Ruang Rawat Bedah } & \\
\cline { 2 - 6 } \multicolumn{1}{c}{ Variabel } & Mean & SD & SE & $\begin{array}{c}p- \\
\text { value }\end{array}$ & Mean & SD & SE & N \\
\hline $\begin{array}{l}\text { Pengetahuan } \\
\text { penanganan masalah } \\
\text { psikologis }\end{array}$ & 23,38 & 0,796 & 0,083 & 0,106 & 23,13 & 0,660 & 0,117 & 124 \\
$\begin{array}{l}\text { Pengetahuan } \\
\text { penanganan masalah } \\
\text { spiritual }\end{array}$ & 19,01 & 1,114 & 0,116 & 0,059 & 19,44 & 1,014 & 0,179 & 124 \\
\hline $\begin{array}{l}\text { Sikap penanganan } \\
\text { masalah psikologis }\end{array}$ & 40,46 & 3,443 & 0,359 & 0,001 & 38,28 & 2,581 & 0,456 & 124 \\
\hline $\begin{array}{l}\text { Sikap penanganan } \\
\text { masalah spiritual }\end{array}$ & 40,11 & 3,926 & 0,412 & 0,008 & 38,16 & 1,868 & 0,330 & 124 \\
\hline
\end{tabular}




\section{Pembahasan}

a. Perbedaan Pengetahuan Perawat Dalam Penanganan Masalah Psikologis dan Spiritual Pasca Bencana Di Ruang Penyakit Dalam dan Rawat Bedah

$$
\text { Berdasarkan hasil uji }
$$

Independent sample t-test didapatkan pengetahuan penanganan masalah dengan penelitian Kiran, Sri, dan Dewi (2017), hampir sebagian perawat berpengetahuan baik $(42.9 \%)$ dan berpengetahuan cukup $(41.4 \%)$ dan sebagian kecil berpengetahuan kurang (15.7\%) dalam memenuhi kebutuhan psikologis dan spiritual klien terminal.

Hasil penelitian ini didukung oleh data demografi dan karaktersitik responden, dimana perawat di Ruang Penyakit Dalam dan Rawat Bedah rata-rata memiliki pengalaman kerja $>2$ tahun dengan $84,8 \%$ dan $84,4 \%$. Hal ini didukung oleh pendapat Mubarak (2011) mengatakan bahwa pengetahuan seseorang dipengaruhi oleh terpapar pengalaman dan pendidikan terakhir yang diperoleh. Hal tersebut sejalan dengan penelitian Emaliyawati (2009) menyebutkan bahwa perawat yang bekerja dalam waktu $>1$ tahun di bangsal perawatan memiliki tingkat pengetahuan dan keterampilan yang lebih baik dibandingkan dengan perawat yang bekerja $<1$ tahun.

Hasil tersebut sesuai dengan penelitian tentang pengetahuan perawat dalam pemenuhan kebutuhan spiritual yang menunjukkan responden mayoritas berpengetahuan baik (84,2\%). Berdasarkan jawaban responden memiliki pengalaman kerja $>5$ tahun sehingga mengakibatkan adanya peningkatan pengetahuan responden tentang kebutuhan spiritual (Destri, 2017). Selanjutnya hasil penelitian yang dilakukan oleh Utami dan Supratman (2009) menyatakan psikologis hasil $p$-value $(0,106)>0,05$ dan pengetahuan penanganan masalah spiritual hasil $p$-value $(0,059)>0,05$ yang berarti tidak ada perbedaan ratarata pengetahuan perawat dalam penanganan masalah psikologis dan spiritual pasien pasca bencana di Ruang Penyakit Dalam dan Ruang Bedah. Hasil penelitian ini sejalan

bahwa perawat yang memiliki pengetahuan baik sebanyak $37,76 \%$, pengetahuan cukup sebanyak $62,24 \%$, dan pengetahuan kurang tidak ada. Dapat disimpulkan bahwa perawat tersebut sebagaian besar memiliki pengetahuan cukup dalam pemenuhan kebutuhan spiritual pasien.

Rabiei, Nakhaee, dan Hosseini (2017) mengenai efek psikologis bencana alam di Iran dengan hasil penanganan dampak psikologis bencana masih lemah, seperti pemahaman penyelamatan dengan prinsip dasar dukungan psikososial dan penghentian dukungan sosial. Manajemen kebencanaan harus ditingkatkan dengan adanya peningkatan dukungan psikososial, peningkatan pendidikan dan memiliki program penanganan dampak psikologis bencana. Moghaddam, Saeed, Khanjani, dan Arab (2014) menyatakan bahwa perlu adanya persyaratan dalam mendukung penanganan bencana berupa dukungan psikologis yaitu kognitif dan intelektual, minat, sikap, pendidikan keterampilan klinis, manajemen bencana yang tepat dan kerjasama kelompok.

Berdasarkan hasil penelitian Yan, Turale, Stone, dan Petrini (2015) yang dilakukan pada perawat di China yang pernah bekerja di satu atau lebih zona bencana memberikan tanggapan tentang pengetahuan yang dibutuhkan perawat dalam penanggulangan bencana untuk penanganan masalah psikologi $(24,67 \%)$. Penelitian lain 
yang dilakukan oleh Fox et al. (2012) menyatakan bahwa seorang perawat harus memiliki pengetahuan tentang psikologis agar dapat melakukan Psychological First Aid (PFA) pada respon bencana agar dapat manangani pasien secara tepat yang mengalami gangguan psikologis akibat bencana.

b. Perbedaan Sikap Perawat terhadap Penanganan Masalah Psikologis dan Spiritual Pada Pasca Bencana Di Ruang Penyakit Dalam dan Rawat Bedah

Hasil uji statistik Independent sample t-test didapatkan sikap perawat dalam penanganan masalah psikologis didapatkan nilai $p$-value $(0,001)<0,05$ dan sikap penanganan masalah spiritual nilai $p$-value $(0,008)<0,05$ yang berarti ada perbedaan sikap penanganan masalah psikologis dan spiritual pasien pasca bencana oleh perawat di Ruang Penyakit Dalam dan Ruang Rawat Bedah. Hasil penelitian didapatkan mayoritas perawat pada kedua ruangan tersebut memiliki tingkat pendidikan terakhir adalah Diploma-III (67,5\%). Menurut Noch, Rompas, \& Kallo (2015) terdapat hubungan tingkat pendidikan dan sikap dengan pelaksanaan prosedur tetap perawatan luka di ruang perawatan bedah dengan nilai inklusi tingkat pendidikan 0,003 dan sikap 0,004 . Hasil penelitian ini semakin tinggi pendidikan seseorang maka semakin baik dalam memberikan pelayanan asuhan keperawatan (Nursalam, 2011).

Lebih lanjut, hasil penelitian Kiran \& Dewi (2017) sikap perawat dalam memenuhi kebutuhan psikologis dan spiritual masih perlu dioptimalkan, sebagian besar responden $(61,4 \%)$ memiliki sikap yang mendukung dan hampir setengahnya responden $(38,6 \%)$ memiliki sikap yang tidak mendukung. Krisis psikologis erat kaitannya dengan masalah moral dan etika seorang perawat menghadapi kejadian bencana. Hasil penelitian menunjukkan masih terbatasnya kesiapan etika perawat untuk tanggap terhadap situasi bencana (Yan, et al, 2015). Sehingga diperlukan sikap professional dari perawat dalam memenuhi kebutuhan psikologis pasien karena efek psikologis jangka panjang dari bencana lebih membahayakan dari pada efek fisik.

Selain itu pelatihan kebencanaan menjadi hal yang perlu diperhatikan. Menurut Hesti, Yetti dan Erwani (2018) tentang faktor-faktor yang berhubungan dengan kesiapsiagaan petugas kesehatan dalam menghadapi bencana gempa dan tsunami dengan hasil terdapat hubungan antara sikap dengan kesiapsiagaan bencana ( $p$ value 0,17). Berdasarkan hasil penelitian Husna, Hatthakit, dan Chaowalit (2011) pelatihan kedaruratan, pendidikan dan keterampilan klinis perawat untuk perawatan tsunami di Banda Aceh dengan hasil perawat di rumah sakit harus meningkatkan pengetahuan dan keterampilan kedaruratan dengan cara harus ikut serta dalam pelatihan kedaruratan, dengan hasil keterampilan klinis perawat masih pada kategori sedang $(3,52)$. Perawat diperlukan untuk mengikuti program pendidikan dan pelatihan kebencanaan untuk meningkatkan kompetensi dalam merespon bencana pada seting rumah sakit secara berkesinambungan.

c. Perbedaan Pengetahuan dan Sikap Perawat Terhadap Penanganan Masalah Psikologis dan Spiritual

Hasil penelitian ini didapatkan tidak ada berbedaan pengetahuan, namun ada perbedaan sikap perawat terhadap penanganan masalah psikologis dan spiritual pada pasien 
pasca bencana. Hasil penelitian ini didukung oleh data demografi reponden dimana perawat Ruang Penyakit Dalam memiliki jenis kelamin perempuan $(16,3 \%)$ dan Ruang Bedah (81,3\%), sedangkan sebagian kecil laki-laki $(16,3 \%$ \& $18,8 \%)$. Berdasarkan hasil penelitian Apriluana, Khairiyati, dan Setyaningrum (2016) tidak ada hubungan signifikan antara jenis kelamin dengan keterampilan dalam penggunaan alat pelindung diri (APD). Menurut Ahmadi (2003) sikap dapat bersifat positif dan negatif. Sikap positif yaitu sikap yang menunjukkan menerima terhadap norma yang berlaku dan sikap negatif merupakan sikap yang menunjukkan penolakan atau tidak menyetujui terhadap norma yang berlaku. Ini berarti sikap menunjukkan kesetujuan atau ketidaksetujuan, suka atau tidak suka seseorang terhadap sesuatu. Menurut Kiran \& Dewi (2017) terbentuknya sikap positif dari perawat dapat dipengaruhi oleh interaksi antar sesama perawat, karena sikap terbentuk dengan interaksi terjadi saling tukar informasi mengenai hal yang berhubungan dengan pelaksanaan asuhan keperawatan. Perawat memperhatikan kebutuhan klien, mengerjakan dan saling berdiskusi mengenai suatu masalah klien. Sikap dapat berhubungan dengan faktor individu seperti ada atau tidaknya sikap menghargai, komunikasi, empati dan sikap mendukung. Menurut Azwar (2000) pembentukan sikap tidak terlepas dari berbagai faktor yang mempengaruhi seperti, pengalaman, kebudayaan, pengaruh orang lain, media massa atau buku, institusi pendidikan, lembaga agama dam faktor emosi dari individu sendiri.

Bila ditelusuri lebih lanjut, karakteristik pendidikan perawat di
Ruang Penyakit Dalam dan Ruang Bedah didominasi oleh perawat berpendidikan Diploma III $(67,4 \%$ dan 62,5\%) dan sebagian kecil perawat memiliki pendidikan terakhir Ners (32,6\% dan 37,5\%). Menurut Elysabeth, Libranty dan Natalia (2017) terdapat hubungan yang signifikan antara pendidikan dengan kompetensi dalan melakukan evidence-based practice ( $\mathrm{p}$-value 0,006). Dimana semakin tinggi tingkat pendidikan seseorang maka semakin baik pula kompetensinya dalam melakukan evidence-based practice nursing. Menurut Elizenberg Elysabeth, Libranty dan Natalia (2017) dalam pendidikan mampu membuat seseorang terampil dalam mencari sumber penelitian, berorganisasi dan bersikap profesional dalam bekerja serta menerapkan praktik berdasarkan bukti. Penulis berpendapat bahwa perawat yang memiliki pendidikan yang tinggi dapat memiliki kompetensi dan sikap profesional yang tinggi ketika memberikan asuhan keperawatan.

\section{Simpulan dan saran}

Berdasarkan hasil penelitian dapat disimpulkan bahwa pengetahuan perawat dalam penanganan masalah psikologis dan spiritual pada pasien pasca bencana tidak ada perbedaan diantara kedua ruangan tersebut yaitu pada Perawat Ruang Penyakit Dalam dan perawat di Ruang Rawat Bedah. Sebaliknya, ada perbedaan sikap perawat dalam penanganan masalah psikologis dan spiritual pada pasien pasca bencana pada perawat di ruang Penyakit Dalam. Hasil penelitian ini dapat menjadi masukan untuk pengembangan kompetensi perawat melalui hospital disaster plan untuk program pendidikan dan pelatihan dalam penanganan masalah psikologis dan spiritual pasca bencana. 


\section{Daftar Pustaka}

Apriluana, G., Khairiyati, L., \& Setyaningrum, R. (2016). Gladys Apriluana, Laily Khairiyati, Ratna Setyaningrum, 3(3), 82-87.

Aten, J. D., Grady, K. A. O., Milstein, G., Boan, D., \& Schruba, A. (2014). Spiritually Oriented Disaster Psychology, (March). https://doi.org/10.1037/scp0000008

Destri, M. (2017). Pengetahuan , Sikap dan Tindakan Perawat dalam Pemenuhan Kebutuhan Spiritual pada Pasien HIV di RSUP . H . Universitas Sumatera Utara. Retrieved from http://repositori.usu.ac.id

Badan Nasional Penanggulangan Bencana. (2018). 1.999 Kejadian Bencana Selama Tahun 2018, Ribuan Korban Meninggal Dunia. Retrieved March, 20, 2019 from https://www.bnpb.go.id/1999-

kejadian-bencana-selama-tahun-2018ribuan-korban-meninggal-dunia

Elysabeth, D., Libranty, G., \& Natalia, S. (2017). Hubungan Tingkat Pendidikan Perawat Dengan Kompetensi Aplikasi EdvidenceBased Practice. Jurnal SKOLASTIK KEPERAWATAN, 1(December).

Fox, J., Burkle, F., Bass, J., Pia, F., Epstein, J., \& Markenson, D. (2012). The Effectiveness of Psychological First Aid. Disaster Medicine and Public Health Preparedness, 6(3), 247-252.

https://doi.org/10.1001/dmp.2012.39

Health, M., Unit, S. U., \& Relief, D. (2016). Technical Guideline For Mental Health In Disaster Situations And.

Hesti, N., Yetti, H., \& Erwani. (2018). Artikel Penelitian Faktor-Faktor yang berhubungan dengan Kesiapsiagaan Bidan dalam Menghadapi Bencana Gempa dan Tsunami di Puskesmas
Kota Padang, 8(2), 338-345.

Husna, C., Hatthakit, U., \& Chaowalit, A. (2011). Do knowledge and clinical experience have specific roles in perceived clinical skills for tsunami care among nurses in Banda Aceh, Indonesia? Australasian Emergency Nursing Journal, 14(2), 95-102. https://doi.org/10.1016/j.aenj.2010.12 .001

Kalanlar, B. (2018). Effects of disaster nursing education on nursing students' knowledge and preparedness for disasters. International Journal of Disaster Risk Reduction, 28, 475-480. https://doi.org/10.1016/j.ijdrr.2017.12 .008

Kiran, Y., \& Dewi, U. S. P. (2017). Pengetahuan dan Sikap Perawat dalam Memenuhi Kebutuhan Psikologis dan Spiritual Klien Terminal. Jurnal Pendidikan Keperawatan Indonesia, 2, 182-189.

Koenig, H. G., Larson, D. B., \& Larson, S. S. (2001). Religion and Coping with Serious Medical Illness, 35.

Li, S.-M., Li, X.-R., Yang, D., \& Xu, N.W. (2016). Research progress in disaster nursing competency framework of nurses in China. Chinese Nursing Research, 3(4), 154-157.

https://doi.org/10.1016/j.cnre.2016.11 .003

Liu, B. F., Fowler, B. M., Roberts, H. A., \& Herovic, E. (2018). Keeping hospitals operating during disasters through crisis communication preparedness. Public Relations Review, 44(4), 585-597. https://doi.org/10.1016/j.pubrev.2018. 06.002

Moghaddam, M. N., Saeed, S., Khanjani, N., \& Arab, M. (2014). Nurses' requirements for relief and casualty support in disasters: a qualitative study. Nursing and Midwifery Studies, 3(1). 
Mubarak, W. I. (2011). Promosi Kesehatan Untuk Kebidanan. Jakarta:

Salemba Medika

National Disaster Management Plan. (2016). National Disaster Management Plan 2016, 7.

Noch, L., Rompas, S. S., \& Kallo, V. (2015). ejournal Keperawatan (e-Kep) Volume 3. Nomor 1. Februari 2015. Ejournal Keperawatan (e-Kep), 3, 18.

Priester, L. De. (2016). Emergency and Disaster Reports An approach to the profile of disaster risk of Indonesia.

Rabiei, A., Nakhaee, N., \& Pourhosseini, S. S. (2014). Shortcomings in dealing with psychological effects of natural disasters in iran. Iranian Journal of Public Health,
Thordardottir, E. B., Gudmundsdottir, B., Petursdottir, G., Valdimarsdottir, U. A., \& Hauksdottir, A. (2018). Psychosocial support after natural disasters in Iceland-implementation and utilization. International Journal of Disaster Risk Reduction, 27(October 2017), 642-648. https://doi.org/10.1016/j.ijdrr.2017.11 .006

Undang-Undang RI No. 24. (2007). Penanggulangan Bencana

Utami, Y. W., \& Supratman. (2009). Hubungan antara pengetahuan dengan sikap perawat dalam pemenuhan kebutuhan spiritual pasien di brsud sukoharjo, 2, 69-74. 